\title{
Los umbrales de lo proscrito. Ritualidad y simbolismo en torno a las cuevas y cenotes entre los mayas peninsulares
}

Resumen: Desde el punto de vista histórico la literatura referente a las cuevas y cenotes ha resultado hasta el momento exigua. Debido a ello, a través de una perspectiva social y cultural de larga duración, el presente trabajo se centra en esclarecer la prevalencia de los espacios proscritos, sus distintas manifestaciones ceremoniales y sus implicaciones entre los mayas coloniales de la península de Yucatán. Así, con la finalidad de ilustrar la coexistencia del sustrato de antigua impronta en un entorno de marcadas disputas entre dominadores y dominados, se privilegia el análisis de las evidencias que permiten dilucidar el proceso de reproducción de la tradición indígena.

Palabras clave: mayas, simbolismo, resistencia, identidad.

\section{The thresholds of the forbidden. Rituality and symbolism of caves and cenotes among the peninsular Mayas}

Abstract: From the historical point of view, the literature on caves and cenotes has been thin. By adopting a social and cultural perspective of the longue durée, the present article focuses on clarifying the prevalence of forbidden spaces, their different ceremonial manifestations and their implications among the colonial Maya of the Yucatan peninsula. Thus, with the goal of illustrating the continuing presence of the ancient substrate in a context of disputes between colonizers and the colonized, this article analyzes evidence that elucidates processes of reproduction and transmission of indigenous traditions.

Keywords: Maya, symbolism, resistance, identity.

\section{Os limiares do proibido. Ritualidade e simbolismo em torno das cavernas e cenotes entre os maias peninsulares}

Resumo: Do ponto de vista histórico a literatura referente às cavernas e cenotes foi até agora muito limitado. Devido a isso, a partir de uma perspectiva social e cultural em longo prazo, o presente trabalho centra-se em esclarecer a prevalência de espaços proibidos, suas diferentes manifestações cerimoniais e suas implicações entre os Maias coloniais da Península de Yucatán. Assim, para ilustrar a prevalência da essência do antigo em um ambiente marcado por disputas entre dominadores e dominados. Nesse sentido, privilegia-se a análise das evidências que permitem elucidar o processo de reprodução da tradição indígena.

Palavras-chave: maias, simbolismo, resistência, identidade.

Cómo citar este artículo: Juan Carrillo González, "Los umbrales de lo proscrito. Ritualidad y simbolismo en torno a las cuevas y cenotes entre los mayas peninsulares", Trashumante. Revista Americana de Historia Socia/14 [2019]: 30-53. DOI: 10.17533/udea.trahs.n14a02

Fecha de recepción: 9 de febrero de 2018

Fecha de aprobación: 14 de noviembre de 2018

Juan Carrillo González: Doctor en Historia por el Centro de Investigaciones y Estudios Superiores en Antropología Social. Actualmente se encuentra adscrito al Posgrado en Estudios Mesoamericanos de la Universidad Nacional Autónoma de México. Correo electrónico: areamaya@yahoo.com 


\title{
Los umbrales de lo proscrito. Ritualidad y simbolismo en torno a las cuevas y cenotes entre los mayas peninsulares*
}

\author{
Juan Carrillo González
}

\section{Introducción}

\begin{abstract}
A través de distintos enfoques, los estudios que versan sobre la importancia Ide las cuevas y cenotes en la sociedad maya han permitido esclarecer su prevalencia. A este respecto, el análisis de los vestigios materiales postulado por la disciplina arqueológica ha contribuido al reconocimiento de sus distintos ámbitos de ocupación y aprovechamiento. De modo similar, la antropología ha hecho lo propio al develar la continuidad del pensamiento demiúrgico mesoamericano en estos espacios. ${ }^{1}$ Sin embargo, desde la perspectiva histórica esta temática solamente ha sido referida en forma tangencial o periférica. Así, la necesidad de incentivar
\end{abstract}

* El presente trabajo se realizó gracias a una subvención otorgada por el Consejo Nacional de Ciencia y Tecnología de México (Conacyt).

1. Edward Wyllys Andrews, Balankanche. Throne of the Tiger Priest (New Orleans: Tulane University, 1970); Henry C. Mercer, The Hill-Caves of Yucatan: A Search for Evidence of Man's Antiquity in the Caverns of Central America (Norman: The University of Oklahoma Press, 1975); Juan Luis Bonor Villarejo, Las cuevas mayas: simbolismo y ritual (Madrid: Universidad Complutense de Madrid / Instituto de Cooperación Iberoamericana, 1989); Ernesto González Licón, Los mayas de la gruta de Loltún, Yucatán, a través de sus materiales arqueológicos (México: Instituto Nacional de Antropología e Historia, 1986); James E. Brady y Juan Luis Bonor Villarejo, "Las cavernas en la geografia sagrada de los mayas", Perspectivas antropológicas en el mundo maya, coords. María Josefa Iglesias y Francesc Ligorred Perramon (Madrid: Sociedad Española de Estudios Mayas, 1993) 75-95; Carmen Rojas, "Prácticas mortuorias en los cenotes", Revista de Arqueología Americana 26 (2008): 197-222; Lisseth Pedroza, "Cenotes y cuevas inundadas de la península de Yucatán. De los primeros pobladores a la Guerra de Castas”, Arqueología Mexicana 105 (2010): 48-52; María Alejandra Espinosa y Gabriela Armentano, "Siliceous Raw Material Sources at La Sierrita de Ticul, Yucatan, Mexico: A First Approach of Lithic Procurement During Late Pleistocene and Early Holocene in the Maya Lowlands", The Exploitation of Raw Materials in Prehistory: Sourcing, Processing and Distribution, eds. Telmo Pereira y otros (New Castle: Cambridge Scholars Publishing, 2017) 121-133. Véase también las publicaciones colectivas en torno a esta temática: Christian Thomas, dir., Las cuevas de Yucatán. La región de Valladolid (Montreuil: Ediciones Xibalbá, 2011); Roberto Romero Sandoval, ed., Cuevas y cenotes mayas. Una mirada multidisciplinaria (México: Universidad Nacional Autónoma de México / Centro de Estudios Mayas, 2016). 
la reconstrucción del pasado (valorando de igual manera el fortalecimiento del diálogo interdisciplinario) conformó el aliciente que dio origen a la presente investigación.

No está de más señalar que la pervivencia de los rasgos esenciales de la tradición maya a lo largo de los siglos que perduró la colonización hispana abrió la posibilidad de dilucidar, a través de una perspectiva de larga duración, los aspectos estructurales de la cosmovisión indígena. Tales elementos, además de traslucir atributos de una dinámica ritual compleja, guardaron una estrecha relación con el pensamiento mítico. Al interior de esta compleja forma de percibir el mundo es posible identificar la importancia simbólica de la geografia sagrada, en este caso asociada a los distintos usos ceremoniales de las cuevas y cenotes, cuyos aspectos nodales se discuten en el presente trabajo. A partir de un conjunto de fuentes documentales procedentes del Archivo General de la Nación de México y el Archivo General de Indias, se llevó a cabo la reconstrucción histórica de la vida ceremonial entre los mayas peninsulares sin perder de vista que la preservación del sustrato de pensamiento de antigua impronta, que se atisba en los ritos propiamente indígenas, guardó una estrecha relación con el fenómeno de oposición a la dominación hispana. Así, el ámbito de preservación cultural y la dilatada pugna inherente a la respuesta activa ante la implantación del sistema colonial (es decir, la capacidad de agencia de los pueblos mayas), conformaron los elementos diacríticos que permitieron esclarecer el fenómeno de continuidad de la tradición mesoamericana.

\section{Oposición, "paganismo” y divergencia}

Las manifestaciones de la ritualidad y la religiosidad indígenas, además de formar parte de una añeja tradición y una manera particular de concebir el mundo, son también expresiones de un dilatado proceso de resistencia, pues los mayas lograron trascender el fenómeno de la desarticulación cultural inherente a la colonización. El proceso de "conquista espiritual” en Yucatán estuvo marcado por contrapuntos diversos. A pesar de los esfuerzos que los religiosos franciscanos llevaron a cabo bajo la tutela de la Corona, y cuya finalidad primordial era la incorporación de los mayas hacia un nuevo ordenamiento religioso - la utopía cristiana del Nuevo Mundo-, la Iglesia se vio en la necesidad de afrontar el reincidente problema de la "heterodoxia nativa”. Dicha conducta, más allá de representar las “vanas observaciones" y "supersticiones de los naturales", conformó la directriz de la respuesta social ante la implantación del sistema colonial, es decir, ante la explotación y el virtual monopolio de las prácticas sagradas en manos de nuevos actores.

Sin dilación, todo ello nos lleva a la formulación de un planteamiento en donde el término de oposición conforma una pieza fundamental para, en primer lugar, identificar las voces del pasado indígena y, posteriormente, tratar de entenderlas y evocarlas. De ahí, entonces, que se intente esclarecer que las denuncias sobre la "transgresión" de la liturgia católica y las disposiciones reales no representan meras elucubraciones de la época, sino hechos concretos a partir de los cuales es posible 
señalar que desde la colonia los mayas reconfiguraron de manera coherente y a partir de su propia cosmovisión su concepción de lo sagrado. ${ }^{2}$ De este modo, no es de sorprender que la "idolatría" nativa de carácter subrepticia, que cobraba vigencia en los cerros, cenotes, cuevas, milpas, la espesura de los montes y los solares de las viviendas, haya tenido una lógica concreta que miraba hacia el pasado y dialogaba con el tiempo, el espacio y el entorno. Esta conducta deliberada, constantemente estigmatizada y en la gran mayoría de los casos malentendida - por representar la antítesis del monoteísmo-, fue denunciada en los albores de la colonia por el fraile Diego de Landa (siglo XVI), y posteriormente por el deán Pedro Sánchez de Aguilar (siglo XVII), el obispo Juan Gómez de Parada (siglo XVIII) y el cura Bartolomé del Granado Baeza (siglo XIX).

La "idolatría" implicó, de igual manera, la coexistencia de los elementos estructurales de la tradición precolombina, que evocaban la reciprocidad entre los mayas y sus antiguas deidades y, asimismo, la continuidad de los ritos a través de los cuales se imbricaban los ámbitos sobrenaturales y profanos. Estas ceremonias perpetuaban los aspectos mnemotécnicos de la cosmovisión, entre ellos, los que se asociaban a los simbolismos de la geografia sagrada.

Las primeras evidencias sobre la "idolatría" colonial en Yucatán, y a partir de las cuales es posible dilucidar el comportamiento ritual asociado a las cuevas y cenotes, se desprenden de las pesquisas realizadas por Diego de Landa en el pueblo de Maní a inicios de la década de 1560, lugar donde el franciscano encontró un gran número de ídolos, cruces quemadas y altares. Las indagaciones efectuadas por el amanuense franciscano y el alcalde mayor Diego de Quijada dieron como resultado el descubrimiento de una amplia actividad en la que se practicaban sacrificios humanos de infantes y personas adultas. En los expedientes sobre las averiguaciones ya señaladas, se indica que los sacerdotes mayas denominados ah k'ines en "contubernio" con los principales y caciques de los pueblos del oriente de Yucatán eran los responsables de efectuar dichas ceremonias. La documentación indica también la existencia de prácticas similares en otros asentamientos. En Yaxcabá, un testigo de nombre Juan Couoh confesó que "los caciques y principales y viejos y demás gente popular del pueblo han tenido y tienen ídolos y han idolatrado con los demás de dicho pueblo, y que tiene ídolos este testigo, los cuales son sesenta ídolos que eran de su padre y los tiene en una cueva escondidos a donde les ha quemado copal". En otros pueblos tales como Tibolón, Francisco Balam y Diego Canbal realizaron sacrificios humanos y luego aventaron los cuerpos al cenote de Tabi para que los dioses "les diese[n] de comer [y] les proveyese[n] de lo necesario y les diese[n] agua para sus milpas". 3

Además de poner de relieve el papel del parentesco en la custodia de los símiles de las deidades hechas de barro y piedra labrada — ya que estas se heredaban de

2. Juan Carrillo González, "Ritualidad y pensamiento de antigua impronta en los pueblos mayas de la Verapaz, Guatemala, 1550-1813”, Ciencias Sociales y Humanidades 3.2 (2016): 63.

3. FranceV. Scholes y Eleanor B.Adams, eds., Don Diego de Quijada, alcalde mayor de Yucatán, 1561-1565, t. 1 (México:Antigua Librería Robredo de José Porrúa e Hijos, 1938) 104-106 y 131. 
padres a hijos-, los sucesos antes señalados proporcionan claras evidencias de una actividad ceremonial en la cual los hombres buscaban congraciarse con los númenes. Era a partir de la benevolencia sobrenatural que se fecundaban los campos, se lograban las cosechas y brotaba del cielo el líquido sustancial para la subsistencia de los hombres, aunque también los favores divinos se utilizaban para afrontar las necesidades cotidianas relacionadas con las afecciones de salud. Así lo indican las pesquisas del Santo Oficio llevadas a cabo en 1582 "en contra de un negro que residía en la estancia de Voholá, perteneciente a la provincia de Xecelchecán” (Campeche), y que respondía al nombre de Cristóbal. En la averiguación, diversos testigos señalaron que el inculpado "comía y bebía lo que los indios le ofrecían al demonio". De acuerdo con los testimonios recabados por el fraile Diego Mejía, Cristóbal estuvo presente en una ceremonia que se llevó a cabo en un cerro en el cual se ofrendaron a las deidades los manjares ceremoniales llamados tut, y una bebida sagrada denominada chuyusha'. Asimismo, en este ámbito ritual las dádivas de copal se utilizaron para sahumar a las deidades y curar a los enfermos. ${ }^{4}$

Hechos similares se llevaron a cabo en los siglos posteriores en Tenabo, Mérida y Campeche. En aquellos sitios, entre 1717 y 1722, un curandero llamado José Zavala realizó diversos rituales en los cuales aludía a los componentes anecúmenos y empíricos (punciones de xooc y aceite de sikiltê), coacción que le permitía restablecer la salud de los enfermos. En dichas ceremonias también utilizó dádivas de balche' y copal. ${ }^{5}$

No está demás señalar que Zavala aludió haber recibido el conocimiento ritual en la "montaña", territorio cuya tardía sujeción sería consumada hasta 1697 . Fue precisamente durante su estancia con los indios montaraces que aprendió los saberes terapéuticos mayas, conocimientos que le fueron legados a través de un rito iniciático que cobró vigencia en los sinuosos umbrales que conducían a los sitios más recónditos de la tierra. Al respecto, el curandero mencionó que:

estando en el monte con los indios huidos de la justicia les observó algunas curaciones, y queriendo mantenerse con ellos les ofreció se casaría con una india hija del capataz, y diciéndole que quería aprender el modo de curar se lo ofrecieron con tal que fuese con ellos a una cueva [... donde] asistió con ellos a los sahumerios que hicieron a unos ídolos, [...] y no queriéndole creer el que se quedaría con ellos, sintiéndose como amarrado por los pies con una cosa que le pareció

4. "El Santo Oficio contra el negro Cristóbal por sospechas de idolatría”, Xecelchecán [Hecelchacán], octubre de 1582. AGN, Ciudad de México, Inquisición, vol. 125, exp. 69, ff. 203r-205v.

5. AGN, Ciudad de México, Inquisición, vol. 1164, exp. 23, ff. 259v-260v. De acuerdo con Alfredo López Austin el cosmos está conformado por distintos ámbitos. El anecúmeno o sobrenatural (espacio-tiempo de los dioses, sustancias y fuerzas) corresponde a los diferentes estratos del hábitat celeste y subterráneo de las divinidades, mientras el ecúmeno (espacio-tiempo mundano) representa el aquí y el ahora, es decir, la morada de las criaturas, ámbito en el que, asimismo, pueden fluir las deidades a través de diferentes umbrales.Alfredo López Austin,"Mitos e íconos de la ruptura del Eje Cósmico: un glifo toponímico de las piedras de Tízoc y del Ex-Arzobispado", Anales del Instituto de Investigaciones Estéticas 89 (2006): 94-96. 
como culebra según el tiento por estar a oscuras, les volvió a asegurar se quedaría con ellos y se casaría con dicha india, con lo cual se salieron y fue con ellos a una casa vieja en donde celebraron el que fuese ya amigo de ellos y se quisiese quedar en su compañía, y después comieron y bebieron las gallinas y agua que sacaron de adentro [de la cueva...], lo cual pasó a los seis meses de estar entre ellos y después como hasta dos años, y los acompañó [...] a cosa de encender copal y poner la comida y otras cosas que ellos hacían. ${ }^{6}$

En otro caso acontecido en 1748 en el barrio de La Mejorada, extramuros de la ciudad de Mérida, un indio de nombre Manuel Mena refirió explícitamente haber participado en un ritual cuya finalidad era la curación de los dolores de hueso y un resfriado que padecía un español llamado Francisco Pantoja. ${ }^{7}$ Manuel Mena dijo también que el rito lo hizo para honrar al "Señor Padre de la Muerte" y salvar las vidas de sus hijos enfermos. En este sentido, indica el cura de Yaxcabá Bartolomé del Granado Baeza, que hasta el año de 1813 el ritual curativo denominado k'ex era una "superstición" que los indios de aquel asentamiento todavía utilizaban, y que consistía en "colgar ciertas comidas y bebidas alrededor de la casa de algún enfermo para el Yuncimil, que quiere decir para la Muerte o Señor de la Muerte, con lo que piensan rescatar la vida del enfermo".

De acuerdo con el Diccionario maya Cordemex, el k'ex es una ceremonia en la que se hace petición del alejamiento de los malos vientos causantes de enfermedades provenientes del inframundo. Tanto en Mérida como en Yaxcabá las evidencias indican que las deidades infraterrestres tales como Yum Cimil todavía se asociaban con las afecciones de salud, malos vientos y calamidades, eventualidades registradas en Tenabo, pueblo en donde el curandero Zavala celebró ritos nocturnos en los que buscaba "atajar el mal aire de la muerte". En un trabajo reciente he identificado a este mal viento con una manifestación de Ixtab-Ixtab'ay, que según

6. AGN, Ciudad de México, Inquisición, vol. 1164, exp. 23, ff. 259v-261v. Con respecto a las prácticas que denotan una tesitura similar es posible señalar algunos casos acontecidos en las inmediaciones de la zona sur de Guatemala. En los albores del siglo XVIII la documentación consigna la prevalencia de un importante grupo de "nagualistas" en los pueblos de Mazatenango, Zapotitlán, Zamayaque y San Bernardino. En estos sitios, los especialistas rituales implementaban para el arte de la curación distintos soplos, pulsaciones, lancetas de pescado, así como hierbas y polvos. De este modo, es posible establecer que los mayas k'iche's, kaqchikeles y tz'utujiles instruían a sus aprendices en el interior de una cueva, sitio en el que asimismo llevaban a cabo importantes ritos de paso en donde los discípulos permanecían por lapsos de hasta treinta días. Una relación pormenorizada de estos hechos puede consultarse en Juan Carrillo González, "Naguales en las poblaciones mayas coloniales. Más allá del sustrato, la transfiguración y la memoria”, Indiana 35.1 (2018): 39-65.

7. "Autos criminales hechos en contra de Nicolás Mena, Manuel Chuc y Francisco Pantoja", Mérida, 4 de mayo de 1748. AGN, Ciudad de México, Inquisición, vol. 908, exp. 14, ff. 169v-170r. Otras menciones concernientes al uso de sahumerios en el ámbito de las ceremonias de curación pueden consultarse en Ramón Arzápalo Marín, ed., El ritual de los bacabes (México: Universidad Nacional Autónoma de México, 1987).

8. AGI, Sevilla, Audiencia de México, 3168.

9. AGN, Ciudad de México, Inquisición, vol. 1164, exp. 23, ff. 259v-260v. 
los testimonios coloniales era un "demonio" al que también se aludía durante las ceremonias curativas.

Para los mayas, la Ixtab'ay era un "espíritu” femenino que vivía en el tronco de la ceiba ( $y a$ 'axche’), árbol cósmico que le permitía circundar el ámbito sobrenatural y profano. La Ixtab'ay representaba la naturaleza salvaje y, debido a ello, podía residir en el monte, o bien en el aktun (que significa cueva o caverna), umbral que conducía al inframundo, tal y como se describe en El ritual de los bacabes. ${ }^{10}$ La entrada a este umbral comenzaba desde el momento en que una persona se alejaba de la superficie de la tierra o se internaba al agua, tal como sucede cuando nos adentramos a las cuevas y cenotes. Sin embargo, esto solamente representa un acceso limitado hacia el borde del inframundo o habitáculo sobrenatural. La penetración hacia el estrato más profundo de este plano solamente era alcanzada por los iniciados que resguardaban los saberes mágico-religiosos y podían efectuar elaborados ritos a partir de los cuales mitigaban los sucesos aciagos tales como plagas, hambrunas y malos temporales que afectaban los ciclos agrícolas. ${ }^{11}$ Estos especialistas rituales, además de curar las "afecciones de cuerpo y alma", tenían la capacidad de transmutarse en animales sagrados como los jaguares, aves o incluso en bolas de fuego. ${ }^{12}$

A este respecto, fray Pedro de Feria refiere a finales del siglo XVI que los indígenas andaban de "cerro en cerro y de cueva en cueva", y que para esto salían en las noches y se reunían en los emplazamientos proscritos donde hacían sus juntas "y trataban de las cosas de sus ritos, y culto al demonio", y decían que se "espiritualizaban, y se convertían en dioses, y las mujeres en diosas, y que ellas como diosas habían de llevar y enviar los temporales". En las averiguaciones que el fraile Feria encargó sobre estas "idolatrías" al clérigo Manuel Acosta, se descubrió también que en las juntas nocturnas de los indios se adoraba a un ídolo que residía en las entrañas de una enorme cueva. ${ }^{13}$

El acceso a las realidades sagradas, como lo ha propuesto Mercedes de la Garza, se efectuaba a través del trance extático o excitación de los sentidos (individual o

10. También se pensaba que la Ixtab'ay seducía a los hombres causándoles locura o muerte. Alfredo Barrera Vásquez, coord., Diccionario maya Cordemex (Mérida: Ediciones Cordemex, 1980) 953; Charles Andrew Hofling y Félix Fernando Tesucún, Tojt'an Maya' Itzaj. Diccionario maya itzajcastellano (Guatemala: Cholsamaj, 2000) 264; Alfredo López Austin, "La magia y la adivinación en la tradición mesoamericana", Arqueología Mexicana 69 (2004): 23. Los aspectos curativos imbricados a la ritualidad y la religiosidad mayas, además de poner de relieve la presencia de las deidades cuyas atribuciones contribuían al remedio de los males, sugieren también un tipo de comportamiento dialéctico entre los númenes residentes del inframundo.

11. Gabriel Espinosa Pineda, "La fauna de Ehécatl", Animales y plantas en la cosmovisión mesoamericana, coord.Yolotl González Torres (México: Consejo Nacional para la Cultura y las Artes / Instituto Nacional de Antropología e Historia / Plaza y Valdés, 2001) 285-289.

12. AGI, Sevilla, Audiencia de Guatemala, 296, ff. 29v-30r; Luis Fernando Restrepo, "Estudios subalternos y tiempo insurgente: memorias Maya-Tzeltal de la rebelión de 1712 en Chiapas", Revista Iberoamericana 201 (2002): 1092-1095.

13. AGI, Sevilla, Patronato Real, 183, exp. 1. 
colectivamente). Dicha condición podía generarse mediante el autosacrificio (sangramiento de pene, lengua, carótida, brazos y piernas), o bien a partir de la ingesta de plantas y bebidas rituales como el balche'. ${ }^{14}$ Este "brebaje" se preparaba con miel de abeja melipona (endémica de la región) y agua proveniente de las cuevas, misma que se recolectaba a través del goteo de las estalactitas, o directamente de los cenotes. La corteza del árbol de balche’ que se dejaba fermentar por varios días, tal como lo señalaron los prelados y gobernadores, conformó un importante insumo para la "idolatría proscrita de los indios”. Así lo refirió Pedro Sánchez de Aguilar a inicios del siglo XVII al señalar que:

despreciando el temor de Dios y de los hombres tomaban sus bebidas llamadas balché, adoraban a los ídolos en sus casas, cavernas y cuevas, los llevaban procesionalmente en hombros, como se descubrió en la provincia de Bacalar, y yo muchísimas veces los aprehendí estando en 1606 con el cargo de vicario provincial en la villa de Valladolid y sus comarcas. ${ }^{15}$

Ese mismo año el obispo Diego Vázquez de Mercado también denunció la ingesta de la bebida psicoactiva, ya no en la costa oriental de Yucatán, sino tierra adentro en las inmediaciones del partido de Valladolid. Durante su visita, el prelado recibió información al respecto de ochenta indios que por "cuadrillas" se reunían para "idolatrar" en diferentes pueblos. Según parece, las juntas se llevaban a cabo en una cueva y, en dicho lugar se advirtió que los sacerdotes involucrados "hacían ceremonias y sahumerios" y que durante el ritual los indios ingerían una bebida que "hacían de ciertas raíces que llaman balché", la cual tenía un aroma y sabor muy peculiar. ${ }^{16}$ Todos estos sucesos confirmaron la "execrable conducta de los naturales" que décadas atrás un español de nombre Martín de Arce había referido durante la apertura del camino hacia la Bahía de la Ascensión en la costa oriental de la península (una de las primeras comisiones del gobierno colonial para la traza de una ruta que desde Yucatán llegaría hasta el Petén y desembocaría en la capital de Guatemala). ${ }^{17}$

A pesar de vedar y vigilar toda conducta sospechosa de los mayas asociada con la "heterodoxia", la impronta cultural precolombina se manifestó de distintas formas en la cotidianidad de la época. De hecho, en los decenios ulteriores que trastocaron la segunda mitad del siglo XVII, el gobernador de Yucatán, Juan Francisco de Esquivel, relató acontecimientos muy similares a los referidos por el obispo Vázquez de Mercado. Indicó que los nativos solían "sembrar arbolillos de cuyas cáscaras hacen una bebida que se llama balché, con que embriagados hacen

14. Mercedes de la Garza, Sueño y alucinación en el mundo náhuatl y maya (México: Universidad Nacional Autónoma de México, 1990).

15. Pedro Sánchez de Aguilar, "Informe contra idolorum cultores del obispado de Yucatán", Hechicerías e idolatrías del México Antiguo, ed. Pilar Máynez (México: Consejo Nacional para la Cultura y las Artes, 2008) 70.

16. AGI, Sevilla, Audiencia de México, 359, ff. 107r-108r.

17. AGN, Ciudad de México, Inquisición, vol. 213 exp. 10. 
muchas ofensas a Nuestro Señor”.Por tal motivo, ante la flagrancia con la cual se manifestaba la "transgresión" de la conducta marcada por los cánones cristianos, y por tener conocimiento de que "muchos indios suelen cometer en sus milpas, cuevas y lugares ocultos y retirados de poblado algunas idolatrías" adorando y perfumando figuras falsas y otras apariencias diabólicas, "negando con tan execrable y detestable delito la adoración y culto que se debe a Dios Nuestro Señor, como creador del cielo y la tierra y nuestro redentor", el gobernador dispuso ciertos escarmientos para erradicar todo rastro de conducta pagana. ${ }^{18}$

Sobre este punto en específico, es menester señalar que la conducta de los mayas no solamente resultó preocupante para el gobierno y la Iglesia de Yucatán durante la época colonial. Así lo demuestran los procesos que, de manera análoga a lo que acontecía en territorio peninsular, se fueron suscitando en las tierras altas de Guatemala tal como lo mencionó el dominico Thomas Gage con relación a las "injurias" realizadas por los indios en el Valle de las Vacas, Pinula y Amatitlán en una cueva en Mixco donde llevaban a cabo "sus antiguallas e idolatrías a una efigie de madera. ${ }^{19}$

Al igual que otros clérigos como Sánchez de Aguilar en Yucatán, Gage proporciona un nítido argumento sobre la persistencia de las prácticas de antigua impronta, hecho que muy probablemente cobró vigencia en el marco del conflicto por el control de la feligresía indígena y la secularización de las parroquias. A pesar de ello, es importante recalcar que los actos que develan la deliberada "transgresión de la liturgia" se enmarcan en un contexto más amplio que trastoca gran parte de los asentamientos de la península, fenómeno que incluso es verificable en términos documentales en Chiapas y Guatemala. En ocasiones, este ámbito de resistencia, como es natural, se inscribía al interior de una cotidianidad que guardaba un cariz velado, poco evidente para los representantes del catolicismo, pero de gran significado para los asentamientos nativos. Estos hechos abren la posibilidad de esclarecer que los fundamentos de la cultura maya actual tienen raíces bastante añejas. Los componentes estructurales de esta compleja forma de interpretar el mundo cobran vigencia en un contexto de larga duración, cuyos elementos temporales se avizoran en distintas regiones, las cuales dibujan una compleja radiografia social que trasluce una interesante dinámica confinada a la trascendencia cultural. De ahí que los aspectos míticos, simbólicos y rituales hayan permanecido imbricados y se hayan perpetuado en el transcurso de las centurias.

Debido a ello, no es de extrañar que las constantes denuncias sobre la conducta impropia de los naturales hayan formado parte de la cotidianidad de la época, y no

18. AGI, Sevilla, Audiencia de México, 361.

19. Tomás Gage, Los viajes de Tomás Gage a la Nueva España. Parte tercera: Guatemala (Guatemala: Editorial Artemis-Edinter, 2000) 70-73. En Guatemala, a mediados del siglo XX, Ledyard Smith reportó la peregrinación ritual de los mayas de Chichicastenango y Quetzaltenango hasta un par de cuevas en Xabaj, lugares cuyos techos literalmente se encontraban ennegrecidos por el humo de las velas y el copal utilizado en las ceremonias. A. Ledyard Smith, Archaeological Reconnaissance in Central Guatemala (Washington: Carnegie Institution of Washington, 1955). 
meras excepciones. Distintos testimonios que versan sobre estos sucesos indican que el monte breñoso fungía como un importante refugio para las tradiciones vedadas. En este sitio, donde coexistían las deidades de la caza y la naturaleza, los indígenas resguardaban las efigies que evocaban la memoria de sus antepasados. ${ }^{20} \mathrm{Se}$ sabe, por ejemplo, que en las inmediaciones de Yobaín se le rendía culto a un ídolo durante las sequías y, asimismo, que otras poblaciones tales como Tibac, Hunucmá, Tixcacal, Mopilá, Sotuta y Dzonotchel participaron en las ceremonias clandestinas que aducían al ciclo agrícola, en las cuales se implementaban distintas viandas alimenticias, bebidas como saka' y balche’, humaredas de copal, rezos, música y danzas nocturnas. ${ }^{21} \mathrm{La}$ importancia de este ejercicio ritual vinculado al entorno de subsistencia de los pueblos devela importantes elementos que, incluso, pueden rastrearse después del ocaso de la dominación colonial. De hecho, las fuentes documentales indican que los remanentes de población dispersa que vivían en los montes aledaños a Chichén Itzá "tenían una estatua antigua que veneraban como a una divinidad", misma que había perdido su color blanco a causa de las "humaredas" de copal y las velas que en su honor se "incendiaban”, prácticas similares a las referidas por Gage en Guatemala durante el siglo XVII. Esta efigie se encontraba:

guardada en una cueva, o más bien mina formada por la extracción de zaccab, una tierra blanca que se mezcla con cal para hacer mortero. Representa a un hombre de barba larga arrodillado, con los brazos levantados de manera que las manos están al mismo nivel de la cabeza; las manos están extendidas y abiertas, con las palmas hacia arriba. ${ }^{22}$

A esta entidad, que según los naturales representaba la deidad de la agricultura, se le rendía culto en el lapso que corresponde a la roza (tumba y quema). Se llevaba al ídolo en procesión a través de un derrotero que iniciaba en el interior de una caverna y culminaba en el centro del terreno que se designaba para el cultivo.

20. Desde la perspectiva indígena, el monte $\left(k^{\prime} a x\right)$ conforma un espacio vital en constante reproducción custodiado por entidades que protegen el entorno y restauran su equilibrio; debido a ello, se pide permiso antes de talar los árboles, ir de cacería y castrar las colmenas. Es, asimismo, un espacio donde se nace e interactúa con la naturaleza que representa el cosmos y alberga los umbrales (cuevas, cenotes, etcétera). Alejandra García Quintanilla, "El dilema de ah kimsah k'ax, 'el que mata al monte': significados del monte entre los mayas milperos de Yucatán”, Mesoamérica 39 (2000): 281-283; Jorge Flores Torres, Los mayas y el control cultural. Etnotecnología, mayaeconomía y pensamiento político de los pueblos centro-orientales de Yucatán (México: Universidad Autónoma de Chapingo / Universidad Autónoma de Yucatán, 1997) 39, 44, 46 y 49-55.

21. Juan Carrillo González, "Entre 'idolatrías y extirpaciones'. Ritos mayas en la provincia de Yucatán", Con el pasado en la mira. Estudios historiográficos, coord. Paola Peniche Moreno (Mérida: Fondo Institucional de Fomento Regional para el Desarrollo Científico, Tecnológico y de Innovación / Consejo Nacional de Ciencia y Tecnología, 2013); Pedro Bracamonte y Sosa, La conquista inconclusa de Yucatán. Los mayas de la montaña, 1560-1680 (México: Centro de Investigaciones y Estudios Superiores en Antropología Social / Universidad de Quintana Roo / Miguel Ángel Porrúa, 2001) 65.

22. Alice Dixon Le Plongeon, Aquí y allá en Yucatán (México: Consejo Nacional para la Cultura y las Artes, 2001) 69-71. 
En este emplazamiento se hacía la petición de la buena quema de los montes encendiendo velas y ofreciendo incienso para alimentar el "órgano olfatorio" de las divinidades relacionadas con los vientos (pahuatunes) y los rumbos cardinales (bacabes). Asimismo, esta ceremonia tenía la finalidad de purificar las tierras de cultivo cuando el monte ya había sido tumbado, y para pedir permiso cuando este se cortaba por primera vez. Ofrendas similares se otorgaban al momento de la siembra para evocar los favores de los seres anecúmenos, obtener fértiles cosechas y resguardar los cultivos de las alimañas que se metían a la milpa y devoraban las plantas jóvenes. Finalmente, al madurar los productos de la milpa y antes de cosechar, los mayas realizaban la ceremonia de primicias recogiendo las mejores mazorcas para ofrendarlas a los númenes y preparar con ellas diversas comidas rituales. Para esta ceremonia se reunían hombres, mujeres y niños muy temprano por la mañana para iniciar la procesión hasta la cueva a donde llevaban "panes de maíz y licor". 23

Los casos anteriormente señalados conforman la clave de una compleja interacción entre cosmovisión y ritualidad, cuyos eslabones permanecieron imbricados al proceso de reproducción cultural en el transcurso de las centurias. Su estructura denota un engranaje, cuyos elementos diacríticos giran en torno al pensamiento mítico, el origen de los hombres y los ciclos de la naturaleza. Debido a ello, las manifestaciones de esta concepción del mundo pueden apreciarse a través de las distintas convenciones que aluden a la funcionalidad de los cenotes y los entornos cavernosos.

La indeleble huella de la "idolatría" que se suscitaba en el contexto colonial no era de ninguna manera fortuita. Era una manifestación latente de la cosmovisión nativa a partir de la cual los habitantes de los pueblos elaboraban "sus creencias y explicaciones sobre el universo", ${ }^{24}$ y, además, establecían sus vínculos coherentes con la naturaleza, el cosmos, el tiempo (cíclico, sagrado y profano) y el espacio. De esta forma, es posible establecer que el conjunto de prácticas indígenas, denostadas como "heterodoxas", tenían la finalidad de entablar una comunicación con lo divino a través del ejercicio ritual. A partir de estas prácticas, se establecía un vínculo entre la cosmovisión y las acciones cotidianas de los hombres. Así lo demuestran las indagaciones llevadas a cabo por el fraile Diego de Landa a inicios de la época colonial en Yucatán, particularmente en las inmediaciones de Yaxcabá, lugar donde se encontró una cueva muy profunda que resguardaba una gran cantidad de ídolos. De esta forma lo indican también los testimonios de religiosos como Pedro Sánchez de Aguilar y Thomas Gage, así como los relatos de los

23. Juan Carrillo González, “Tunk’ul: Análisis de un instrumento musical maya en contextos rituales durante la Colonia", Flower World, Music Archaeology of the Americas / Mundo Florido, Arqueomusicología de las Américas 1 (2012): 127-136; Carrillo, "Entre "idolatrías y extirpaciones"” 90-106; Le Plongeon 69-71; AGI, Sevilla, Audiencia de México, 3168.

24. Johanna Broda, "Introducción", Cosmovisión, ritual e identidad de los pueblos indígenas de México, coords. Johanna Broda y Félix Báez-Jorge (México: Consejo Nacional para la Cultura y las Artes / Fondo de Cultura Económica, 2001) 15-45. 
viajeros decimonónicos, quienes han reiterado las apreciaciones sobre una extensa actividad ceremonial desarrollada al interior de los entornos cavernosos. ${ }^{25}$

Sobre este punto en particular, es posible señalar que desde tiempos remotos las cuevas han conformado un lugar sagrado por excelencia. Según el Popol Vuh, los primeros hombres que poblaron la tierra fueron a recibir sus dioses a Tulán Zuivá, al Vucub Pec, es decir, a la cueva de Tulán o las Siete Cuevas, lugar que en la tradición mexica se conoce como Chicomóztoc. ${ }^{26}$ Además de los orígenes míticos, a las cuevas también se les asocia con los elementos generadores de vida en muchas partes de Mesoamérica. De modo similar a lo que acontece con las montañas y cerros, las cuevas han conformado un importante refugio para el desempeño "del núcleo más antiguo de los ritos mesoamericanos asociados a los elementos como el agua y la tierra". ${ }^{27}$ En estos espacios versátiles se realizaban sepulturas y ceremonias que incluían el ofrecimiento de sangre mediante el autosacrificio, actos que en ocasiones se ejecutaban al son de las voces instrumentales del caracol, el tambor y las flautas. Así lo demuestran las pinturas elaboradas en sus túneles, los depósitos cerámicos y los altares que han sido localizados en su interior en diversas partes de Yucatán, Belice, Chiapas y Guatemala. ${ }^{28}$

Como lo indican diversas fuentes, tales como las cartas del prelado Vázquez de Mercado en 1606, las disposiciones del gobernador Esquivel fechadas en 1666, así como el testimonio del curandero José Zavala en 1724, en las entrañas rocosas de las cuevas se transmitía el conocimiento especializado y se ingerían bebidas como el balche'. ${ }^{29}$ Pero también era debido a su connotación etérea que a estos espacios se les vinculaba estrechamente con la fertilidad. Así lo expresó fray Bartolomé de las Casas en su Apologética historia sumaria. Este manuscrito indica que los mayas llevaban a cabo cierto tipo de expiaciones cuando una pareja encontraba dificultades para procrear. Para ello, efectuaban una purificación ritual que consistía en la abstinencia sexual (por tiempo de un mes y medio aproximadamente) y el consumo

25. Diego de Landa, Relación de las cosas de Yucatán (México: Porrúa, 1986); Sánchez 73, 156, 190; Gage 70-73; AGI, Sevilla, Audiencia de México, 3168.

26. "Popol Vuh. Las antiguas historias del Quiché", Literatura maya, comp. Mercedes de la Garza (Caracas: Biblioteca Ayacucho, 1992) 63; Enrique Florescano, Memoria mexicana (México: Fondo de Cultura Económica, 2004) 213.

27. Johanna Broda y Alejandro Robles, "De rocas y aires en la cosmovisión indígena: culto a los cerros y al viento en el municipio de Tepoztlán”, Historia y vida ceremonial en las comunidades mesoamericanas: los ritos agrícolas, coords. Johanna Broda y Catharine Good Eshelman (México: Consejo Nacional para la Cultura y las Artes / Instituto Nacional de Antropología e Historia / Universidad Nacional Autónoma de México, 2004) 280. Incluso se ha postulado que en la región de los Andes los incas refieren que el parto primigenio de la tierra que dio origen a la humanidad fue llevado a cabo en una cueva llamada tampu tocco. Silvia Limón Olvera, Las cuevas y el mito de origen: los casos inca y mexica (México: Consejo Nacional para la Cultura y las Artes, 1990) 11-13.

28. Claude-François Baudez, Una historia de la religión de los antiguos mayas (México: Universidad Nacional Autónoma de México / Centro Francés de Estudios Mexicanos y Centroamericanos / Centre Culturel et de Coopération pour l'Amérique Centrale, 2004) 463-478.

29. AGI, Sevilla, Audiencia de México, 359; Sánchez 36. 
de especias como la sal. La pareja, además de seguir una rigurosa dieta a base de pan seco o maíz, debía pasar varios días en una cueva designada por un sacerdote. Pernoctar en las entrañas de las cavernas simbolizaba un acercamiento al útero de la madre tierra, cuyo rito aludía a la tan anhelada fertilidad que podía ser conferida a los seres terrenales al reposar en su interior. ${ }^{30}$

Al denunciar las cuevas, cenotes, montes y cerros como lugares "perniciosos", los curas párrocos y prelados ponían en evidencia los conceptos de la cosmovisión que aludían a la geografía simbólica y sus manifestaciones. Incluso muchas de ellas todavía coexisten entre diversos grupos mayas, pues además de los yucatecos, los tzotziles de Zinacantán (Chiapas) consideran a las cuevas, "los manantiales, las montañas, las cañadas, los peñascos y los árboles" como parte de un paisaje natural en el que residen las deidades. En él, las cruces son símbolos o marcadores que denotan lugares específicos en donde se desenvuelven los rituales, o bien indican los límites entre el ámbito ecúmeno y anecúmeno. Los elementos del paisaje sacralizado tienen la función de establecer las fronteras o linderos de los pueblos, es decir, conforman mojoneras naturales cuyos rasgos definen los espacios sociales. Así lo dio a entender en su testamento Pedro Noh en 1716 al heredarle a su hijo unas porciones de tierra que se encontraban en los montes del pueblo de Homún, y se hallaban:

como a tres cuadras de Xucen, al bajío de una tierra negra [...] hace esquina girando al oriente pasando por la boca del paso de Tikoch, debajo de un rosal está una mojonera, [que] pasa de largo hasta el paso de Kocholá, en donde hace esquina girando para el sur hasta una aguada, [y] pasa de largo hasta llegar a Xpech, en donde hace esquina dando al poniente hasta el paso de Mucil, girando hasta la cueva Aktum Balam hasta llegar al paso de Holochil. ${ }^{31}$

La geografia sagrada es polivalente, pues también encarna la presencia de los ancestros, es decir, los descendientes primigenios de las deidades. La estructura del pensamiento maya articulado a la pervivencia de una herencia ancestral puede rastrearse hasta el período Clásico a través de las evidencias plásticas. En dicha época, los mayas se abocaron a la elaboración de escenas en las cuales los ancestros

30. Bartolomé de las Casas, Apologética historia sumaria: cuanto a las cualidades, disposición, descripción, cielo y suelo destas tierras, y condiciones naturales, policías, repúblicas, maneras de vivir y costumbres de las gentes destas Indias Occidentales y Meridionales, cuyo imperio soberano pertenece a los reyes de Castilla (México: Universidad Nacional Autónoma de México, 1967); Noemí Cruz Cortés, Las señoras de la luna (México: Universidad Nacional Autónoma de México, 2005) 71-74; Francisco Ximénez, Historia de la provincia de San Vicente de Chiapa y Guatemala de la Orden de Predicadores (Guatemala: Sociedad de Geografía e Historia de Guatemala, 1929) 284-287.

31. "Testamento de Pedro Noh", Homún, 1716, citado en Paola Peniche Moreno, Ámbitos del parentesco: la sociedad maya en tiempos de la Colonia (México: Centro de Investigaciones y Estudios Superiores en Antropología Social / Miguel Ángel Porrúa, 2007) 256-257; Alejandro Sheseña Hernández, comunicación personal (2011). 
acompañaban a los herederos al trono durante los ritos que marcaban su ascensión al poder. ${ }^{32}$

Por otro lado, las cuevas naturales, además de umbrales de convergencia entre los ámbitos ecúmenos y anecúmenos, representan la entrada al corazón de la tierra tal como lo indican las evidencias que ponen de relieve la "recalcitrante heterodoxia indígena" señalada por los religiosos. Asimismo, conforman "conductos geológicos para la movilización del agua subterránea" y al unísono simbolizan los umbrales que conducen al ámbito sobrenatural. De modo similar, las cuevas artificiales presentes en algunos sitios arqueológicos emulan dichas características al evocar los aspectos simbólicos de las cuevas naturales. De esta manera lo ha planteado David Brady al proponer la existencia de "un paisaje conceptual compartido" en Mesoamérica, en el cual la mano del hombre reproduce los elementos faltantes en las geografias particulares de cada región. A este respecto, indica que, si bien existe una correlación entre la replicación de los aspectos mítico-cosmogónicos a partir de la construcción de pirámides a manera de montañas que desde la tierra ascienden al cielo, entonces, no sería tan descabellado pensar que dicho postulado podría aplicarse análogamente a la morfología artificial de las cuevas encontradas en los sitios precolombinos. ${ }^{33}$

\section{Una mirada al interior de un entorno proscrito}

Es menester señalar que no es posible soslayar en el análisis de los entornos cavernosos los cuerpos de agua que en su interior se encuentran. Por tal motivo, es imprescindible identificar y asimismo integrar a la discusión aquellos componentes que permiten ilustrar su importancia. La correlación entre elementos como cueva, pozo, cenote y agua es notable en lo que concierne al pensamiento mítico y las prácticas rituales indígenas, aunque también es posible identificarla en la esfera de la dimensión cotidiana que alude a la utilidad de estos recursos.

A este respecto, los relatos surgidos en los albores de la segunda mitad del siglo XVI, tales como el de Tomás López Medel, indican que en Yucatán "la mayor parte del agua corría por debajo de la tierra", y también que en muchos sitios de la provincia "proveyó la naturaleza de su propio movimiento, sin artificio humano, unos como estanques y lagunas de agua tan hondas que desde la superficie de la tierra hasta el agua hay en algunos a diez y doce y a quince brazas". El oidor real y visitador también señaló haber visto “algunos de estos estanques que los indios y naturales llaman en su lengua cenotes, y son algunos tan anchos como un tiro de

\section{Florescano 87-91 y 100-106.}

33. James E. Brady, "La importancia de las cuevas artificiales para el entendimiento de los espacios sagrados en Mesoamérica", Espacios mayas: representaciones, usos y creencias, eds. Alain Breton y otros (México: Universidad Nacional Autónoma de México / Centro Francés de Estudios Mexicanos y Centroamericanos, 2003) 148-149 y 151. 
piedra y son redondos y circulares por la mayor parte, y de una y otra parte y por todos ellos de una peña tan tajada como si la hubieran labrado a mano". ${ }^{4}$

En Yucatán se les denomina cenotes a los cuerpos de agua que generalmente se ubican en un entorno cavernoso. ${ }^{35} \mathrm{Si}$ prestamos atención al vocablo maya que hace referencia a este medio acuoso, es decir, $t s^{\prime}$ onot, podemos avizorar que este, en primera instancia, puede interpretarse como "caverna con agua depositada" (en su interior), e incluso como abismo o profundidad sin fondo. Pero también el Diccionario maya Cordemex menciona que ts'onot puede significar depósito de "agua dulce muy hondo o pozo". ${ }^{36}$ Es claro que este vocablo tiene una doble nomenclatura que, por un lado, alude a una dimensión espacial o emplazamiento y, por el otro, hace referencia en estricto sentido al elemento hídrico, lo que conduce a dilucidar la relevancia de ambos aspectos al interior de la dilatada estructura simbólica que corresponde a la sociedad indígena peninsular.

Asimismo, la correlación anteriormente referida resulta plausible para entrever que las distintas acepciones que corresponden a un emplazamiento o abismo claramente aluden al tránsito hacia el inframundo. El ejemplo más concreto sobre esta apreciación lo encontramos en el entierro 116 del Templo 1 de Tikal (del período Clásico Tardío), lugar donde se recuperaron huesos grabados que contienen escenas metafóricas que sugieren que los mayas equiparaban la muerte con "el hundimiento de una canoa en el inframundo acuoso". Pero también habría de señalarse que la arquitectura de los sitios prehispánicos buscaba emular una vinculación con el plano celeste y el inframundo, como se evidencia en Mayapán, lugar donde la estructura principal se encuentra edificada justo al lado del cenote Ch'en Mul, lo que al parecer es una manifestación del complejo cueva-pirámide. ${ }^{37}$

Además de las alegorías míticas y arquitectónicas sobre el inframundo, la dimensión espacial de la ritualidad indica que las cuevas y cenotes conformaban sitios que, debido a sus características simbólicas, podían considerarse idóneos para el desempeño ceremonial. Sin embargo, en un sentido más amplio el inframundo

34. Esta misma relación señala que en los cenotes existía "un género de pescadillos como anguilas, que llaman bagres, con cuero sin escama, que tienen buen comer, y algunos se sacan de razonable tamaño de los cenotes, y péscanlos con anzuelos". Tomás López Medel, De los tres elementos. Tratado sobre la naturaleza y el hombre del Nuevo Mundo (Madrid: Alianza, 1990) 83-84.

35. En la península de Yucatán gran parte de los cuerpos de agua son de tipo subterráneo. Estos se forman por la "disolución y ruptura en sus rocas kársticas altamente permeables", cuya utilidad puede rastrearse desde el período Preclásico. Sin embargo, esto no cancela de ningún modo la existencia de algunos cenotes denominados como de tipo abierto (o de boca exterior), como el que se encuentra, por ejemplo, en el sitio arqueológico de Dzibilchaltún. Teresa Rojas Rabiela y otros, Cultura hidráulica y simbolismo mesoamericano del agua en el México prehispánico (México: Instituto Mexicano de Tecnología del Agua / Centro de Investigaciones y Estudios Superiores en Antropología Social, 2009) 221.

36. Barrera 889-890.

37. Merideth Paxton, The Cosmos of the Yucatec Maya. Cycles and Steps from the Madrid Codex (Albuquerque: University of New Mexico Press, 2001); Linda Schele y Mary Ellen Miller, The Blood of Kings: Dynasty and Ritual in Maya Art (Nueva York: George Braziller, 1986). 
también alude a un entorno anecúmeno y a las respectivas entidades que en su interior residían, pues así lo indican los ritos curativos ocurridos en Tenabo (Campeche) entre 1722 y 1724 efectuados por el curandero Zavala, quien, además de remediar las afecciones, buscaba congraciarse con las deidades que propiciaban las enfermedades y enviaban los malos vientos (iko'ob). De hecho, estas acepciones también fueron registradas en los siglos subsecuentes en la relación de Yaxcabá (1813) y en la crónica de Le Plongeon que indicaba que en las cavernas de Yucatán "brotaban humos o vientos que mataban a las personas". 38

Por otro lado, las dádivas que se ofrendaban en los rituales también sugieren la emulación de los planos celestes e infraterrestres. Así lo indican las ceremonias que tenían la finalidad de atraer las lluvias y cobraron vigencia en el pueblo de Xohuayán, lugar donde los especialistas rituales ofrendaban a "los Señores del Cielo", en cada uno de los puntos cardinales, "panes de doce capas divididos en dos secciones" y, además, otro pan hecho de carne de armadillo (w'eech) que coronaba la ofrenda. ${ }^{39}$ Según parece, estas dádivas guardaban una estrecha relación con los denominados trece cielos del ámbito anecuménico superior. Por otro lado, los nueve pisos del ámbito anecuménico inferior podrían estar replicados, simbólicamente, en las nueve jícaras de cacao y chile que en el interior de las cuevas se ofrendaban a las deidades del inframundo durante la ceremonia del hetz lu'um y en otros ritos de transmisión del conocimiento entre curanderos y aprendices que ya se han señalado. ${ }^{40}$ Lo anterior sugiere que la dimensión espacial del rito evoca también uno de los arquetipos principales de la cosmogonía maya, es decir, una interacción tripartita cuya convención se refiere al plano ecuménico terrestre, lugar donde habitan los hombres, y también a los planos anecuménicos que por encima y debajo del mundo terrenal se proyectan. Dicha acepción se relaciona, por un lado, con el ya'axche' (árbol del mundo) o axismundi (quinta dirección) cuyas ramas alcanzan los diversos estratos del cielo (a la vez que el tronco conforma un umbral que comunica con la tierra, mientras las raíces conectan con el inframundo) y, por el otro, con el complejo cueva-pirámide. La cueva representa al inframundo, mientras la pirámide simboliza la montaña-cielo, así como la trayectoria ascendente y descendente del sol en su paso por la bóveda celeste y su cenit o punto de esplendor en el firmamento. ${ }^{41}$

Lo anterior sugiere también que los mayas concibieron el tránsito hacia los planos superiores como trayectos escalonados y, análogamente, puede sugerirse

38. Le Plongeon 69-71; AGI, Sevilla, Audiencia de México, 3168.

39. Jesús Guzmán Urióstegui, “El fogón y la milpa.El espacio entre los mayas de Xohuayán,Yucatán”, Dimensión Antropológica 39 (2007): 104-106.

40. Guzmán 106-108; AGI, Sevilla, Audiencia de Guatemala, 376, ff. 9v-16r; Carmelo Sáenz de Santa María, "Una visión etnorreligiosa de la Guatemala de 1704, según fray Antonio Márgil de Jesús", Revista de Indias 41 (1981): 454-457.

41. Juan Luis Bonor Villarejo y Carolina Martínez Klemm, "Traducción y comentarios al artículo de J. Eric S. Thompson "The Role of Caves in Maya Culture", Boletín Americanista $42-43$ (1992-1993): 413-416; López Austin, "La magia” 22-25. 
que la concepción del descenso al inframundo (xibalba') se suscitaba de manera escalonada hacia su estrato más profundo. En esta representación simbólica del cosmos, el inframundo es concebido como una pirámide invertida en donde el sol podía transitar cada vez que abandonaba el firmamento. ${ }^{42}$

\subsection{El medio hídrico}

El segundo componente de la nomenclatura que señalé en líneas anteriores, el elemento hídrico, alude tanto a los cuerpos de agua como a los diferentes medios de acuosidad. De hecho, las fuentes documentales indican que el medio acuático tuvo un papel preponderante al aportar significativos insumos para la actividad ritual. Como punto de partida a este respecto, es posible señalar que el agua que se recolectaba en las cuevas conformaba un ingrediente fundamental para la preparación de bebidas ceremoniales (balche' y saka'). Otro ejemplo de la utilidad del recurso hídrico en la preparación de bebidas rituales se desprende de los hechos acontecidos en Xecelchecán (Campeche) en 1582, pues en dicho lugar el "agua del cielo" se utilizó para la elaboración de un "elixir ceremonial" que tenía propiedades curativas (chuyusha'). ${ }^{43}$

El medio acuático conformó el elemento generador de la vida terrenal y, debido a ello, las alegorías míticas refieren su connotación sagrada. Representa, asimismo, uno de los elementos sustanciales para la conservación de la vida. Por tanto, no es fortuito que las concepciones demiúrgicas mayas refieran ciertos paralelismos entre agua y fertilidad. Según el Popol Vuh, antes de la creación:

todo estaba en suspenso, todo en calma, en silencio: todo inmóvil y callado, y vacía la extensión del cielo. Esta es la primera relación, el primer discurso. No había hombres, ni un animal, [...] ni piedras, cuevas, barrancas, hierbas ni bosques [...] No se manifestaba la faz de la tierra. Sólo estaban el mar en calma y el cielo en toda su extensión. ${ }^{44}$

Toda esta pasividad se debía a que "nada había sido dotado de existencia” y, por ende, la tierra se encontraba estática en su totalidad. El agua estaba en reposo, y el mar estaba inmóvil al igual que las nubes en el cielo. Fue entonces, por obra de las deidades, que la tierra emergió de las profundidades de las aguas primigenias y, de esta forma, es que surgieron "las montañas y los valles; se dividieron las corrientes de agua, los arroyos se fueron libremente entre los cerros, y las aguas quedaron

42. En este mismo sentido es posible señalar que las cuatro caras de las estructuras piramidales (celestes e infraterrestres) conforman las "cuatro regiones del cielo y las del inframundo", y ambas tienen contacto con la tierra, cuya acepción alude a una superficie plana y cuadrangular. Guzmán 103-109; López Austin, "La magia” 20-26.

43. "El Santo Oficio contra el negro Cristóbal por sospechas de idolatría”, Xecelchecán [Hecelchacán], octubre de 1582. AGN, Ciudad de México, Inquisición, vol. 125, exp. 69, ff. 203r-205v.

44. "PopolVuh" 12-13. 
separadas cuando aparecieron las altas montañas". ${ }^{45}$ El pasaje anteriormente señalado es sin duda una interesante metáfora que sugiere que el agua de los ríos, así como aquella que se encontraba ubicada en el interior de los cenotes y la madre tierra (subsuelo), representaba el elemento sustancial a partir del cual cobró vida y emergió el mundo de los seres vivos. Tampoco hay que perder de vista que una gran diversidad de entidades mayas tales como Chaak e Itzamná tenían entre sus atribuciones la capacidad de provocar las lluvias y, por tanto, las gotas de agua provenientes del firmamento eran consideradas manifestaciones de los favores anecúmenos que permitían la reproducción del medio hídrico. Además, las lluvias formaban el eslabón principal de una gran sinergia vital. ${ }^{46}$

En el polivalente mundo acuático destaca también la prevalencia del mar, pues de sus profundidades se obtenían importantes insumos para la subsistencia y el comercio. ${ }^{47} \mathrm{El}$ mar cobijaba entre sus olas importantes actividades como la pesca, y las ceremonias alusivas a esta actividad fueron registradas durante la colonia en diversas partes de la península de Yucatán, tanto en la Bahía de la Ascensión (la costa oriental en el año de 1587 por Martín de Arce) como en la costa de Tizimín (zona nororiental de la península a inicios del siglo XVII por Pedro Sánchez de Aguilar). ${ }^{48}$

El agua, como elemento de primer orden en el pensamiento maya, además de estar cargada de un fuerte simbolismo, contiene diversas características que se imbrican a la biodiversidad, pues así lo indican los elementos iconográficos que evocan escenas en donde se aprecian diversos nichos ecológicos. Además de tener múltiples propiedades, cubría una variedad de funciones. De ahí que los ritos asociados al medio acuático hayan tenido un papel capital en Mesoamérica y el área maya. ${ }^{49}$ Sobre este punto en particular, es posible señalar que toda esta advocación tenía la finalidad de entablar una comunicación con las deidades que comúnmente se asociaban a los elementos de la naturaleza y conferían su benevolencia a los seres mundanos. ${ }^{50}$

45. "PopolVuh" 12-14. Esta metáfora guarda una estrecha relación con la representación de la tierra como caparazón de tortuga, misma que enfatiza su capacidad de emerger de las profundidades, pasaje que asimismo se vislumbra en distintos momentos en la iconografia maya de la creación.

46. En las obras plásticas prehispánicas, las cuentas de jade representan las gotas de agua que encarnan el aliento esencial de los hombres, y era a través de ellas que respiraba el mundo. Simbolizan también el resurgimiento de la vida, su conservación y el continuum de los ciclos estacionales. Más que ornamentos, las cuentas de jade constituyen en sí mismas una estructura del cosmos que portan las deidades, los sacerdotes y los hombres. Mediante las ofrendas y rituales estos últimos reproducían su afán de establecer una comunión con el orden y la continuidad del cosmos, así como trascender al caos y la muerte. Rojas y otros 241.

47. Rojas y otros 187.

48. AGN, Ciudad de México, Inquisición, vol. 213, exp. 10; Sánchez 176-180.

49. Es menester precisar que el medio acuático hace referencia a un conjunto de características y diferencias acordes tanto a la ubicación como a las particularidades donde este elemento podía encontrarse.

50. De Landa 9, 55, 91-88, 118-122, 131-155. 
Durante los rituales, los mayas también acostumbraban arrojar a las víctimas de los sacrificios humanos al interior de los cenotes, así lo indican las evidencias osteológicas obtenidas, por ejemplo, de las profundidades del Cenote Sagrado de Chichén Itzá, los sucesos que cobraron vigencia en el cenote de Tabi a inicios de la época colonial, que ya se han señalado, así como la Relación escrita por el franciscano Diego de Landa. En este escrito se menciona que los indios, además de tener la costumbre de "echar a los hombres hacia aquellos lugares" en los sacrificios que realizaban en "honor a sus dioses en tiempos de secas", arrojaban "otras muchas cosas de piedras de valor y que tenían preciadas". ${ }^{51}$ El descenso de las ofrendas que se vertían hacia el interior de las cuevas o cenotes desde un nivel superior "podría equipararse inversamente al ascenso del cordón umbilical de copal hacia la bóveda celeste" ${ }^{52}$ Este acto, además de conformar la esencia de la experiencia religiosa entre hombres y dioses, evocaba la presencia de los creadores. De igual forma, servía para mitigar el extenuante desgaste que las deidades sufrían en su cotidiana tarea de generar las energías primordiales del universo, ${ }^{53}$ es decir, incitaban el accionar de la naturaleza y el cosmos, la dualidad y la dialéctica de la vida en su conjunto tal como lo señala el Popol Vuh.

\section{Consideraciones finales}

El ejercicio ritual imbricado a la geografia sagrada devela una compleja estructura de pensamiento que mira hacia el pasado y dialoga con el entorno (natural, cultural y social). Al interior de esta compleja forma de percibir el mundo se conjugan múltiples aristas del espacio-tiempo que resultan imprescindibles para la interacción entre las deidades y los hombres. En este caso en particular, la identificación de las acepciones vinculadas a las cuevas, cenotes y medio acuático abrió la posibilidad de esclarecer que el culto llevado a cabo en estos sitios, además de evocar la memoria de las entidades creadoras, recreaba las alegorías sobre el origen del mundo. Esta antigua forma de pensar, al sedimentarse en la memoria colectiva, logró trascender las centurias, debido a que su permeabilidad le confirió la capacidad de resignificar contenidos exógenos.

Los distintos elementos del ámbito ceremonial relacionado con las cuevas y cenotes, vistos a través de una dinámica de larga duración, traslucen un dilatado proceso de resistencia ante la desarticulación cultural. De hecho, la reincidente "idolatría" denunciada por los clérigos conformó una pieza fundamental que permitió esclarecer la coexistencia de la antigua tradición. Esto indica, asimismo, que la sociedad indígena logró modificar los parámetros de la dominación colonial.Así,

\section{De Landa 83-87.}

52. Baudez 66.

53. Alfredo López Austin y Leonardo López Luján, "El sacrificio humano entre los mexicas", Arqueología Mexicana 103 (2010): 30. 
las manifestaciones de la respuesta social activa y deliberada dejaron una impronta indeleble en el transcurso de las centurias.

El ejercicio de centrar la mirada en un ámbito velado que se mantuvo al margen de la panóptica vigilancia eclesial permitió esclarecer la coexistencia proscrita de una compleja forma de entender e interpretar el mundo. Las evidencias presentadas también abrieron la posibilidad de identificar la prevalencia de un engranaje social que giraba en torno al resguardo del conocimiento ritual especializado, las relaciones de parentesco y el vínculo con los antepasados. ${ }^{54}$ De este modo, fue posible dilucidar que la traza de un entorno vedado, cuya cotidianidad denota nítidamente los elementos sustanciales de la ritualidad maya que se articulan a la tradición mesoamericana, guardó una estrecha correlación con el paisaje sacralizado y sus contenidos simbólicos. Por todo lo anterior, se postula que los mecanismos de reproducción cultural de la sociedad indígena colonial, además de coadyuvar a la cohesión social, resultaron fundamentales para la preservación de los aspectos mnemotécnicos de la cosmovisión, la vida ceremonial y el pensamiento de antigua impronta.

\section{Fuentes}

\section{Manuscritas}

Archivo General de la Nación, Ciudad de México (AGN) Inquisición

Archivo General de Indias, Sevilla (AGI)

Audiencia de México

Audiencia de Guatemala

Patronato Real

\section{Impresas}

De las Casas, Bartolomé. Apologética historia sumaria: cuanto a las cualidades, dispusición, descripción, cielo y suelo destas tierras, y condiciones naturales, policías, repúblicas, maneras de vivir y costumbres de las gentes destas Indias Occidentales y Meridionales, cuyo imperio soberano pertenece a los reyes de Castilla. México: Universidad Nacional Autónoma de México, 1967.

De Landa, Diego. Relación de las cosas de Yucatán. México: Porrúa, 1986.

Gage, Tomás. Los viajes de Tomás Gage a la Nueva España. Parte tercera: Guatemala. Guatemala: Editorial Artemis-Edinter, 2000.

López Medel, Tomás. De los tres elementos. Tratado sobre la naturaleza y el hombre del Nuevo Mundo. Madrid:Alianza, 1990.

"PopolVuh. Las antiguas historias del Quiché". Literatura maya. comp. Mercedes de

54. Carrillo, "Naguales" 60. 
la Garza y otros. Caracas: Biblioteca Ayacucho, 1992.

Sánchez de Aguilar, Pedro. "Informe contra idolorum cultores del obispado de Yucatán”. Hechicerías e idolatrías del México Antiguo. Ed. Pilar Máynez. México: Consejo Nacional para la Cultura y las Artes, 2008.

Ximénez, Francisco. Historia de la provincia de San Vicente de Chiapa y Guatemala de la Orden de Predicadores. Guatemala: Sociedad de Geografia e Historia de Guatemala, 1929.

\section{Bibliografía}

Andrews, Edward Wyllys. Balankanche. Throne of the Tiger Priest. New Orleans:Tulane University, 1970.

Arzápalo Marín, Ramón. Ed. El ritual de los bacabes. México: Universidad Nacional Autónoma de México, 1987.

Barrera Vásquez, Alfredo. Coord. Diccionario maya Cordemex. Mérida: Ediciones Cordemex, 1980.

Baudez, Claude-François. Una historia de la religión de los antiguos mayas. México: Universidad Nacional Autónoma de México / Centro Francés de Estudios Mexicanos y Centroamericanos / Centre Culturel et de Coopération pour l'Amérique Centrale, 2004.

BonorVillarejo, Juan Luis. Las cuevas mayas: simbolismo y ritual. Madrid: Universidad Complutense de Madrid / Instituto de Cooperación Iberoamericana, 1989.

Bonor Villarejo, Juan Luis y Carolina Martínez Klemm. “Traducción y comentarios al artículo de J. Eric S. Thompson 'The Role of Caves in Maya Culture"”. Boletín Americanista 42-43 (1992-1993): 395-424.

Bracamonte y Sosa, Pedro. La conquista inconclusa de Yucatán. Los mayas de la montaña, 1560-1680. México: Centro de Investigaciones y Estudios Superiores en Antropología Social / Universidad de Quintana Roo / Miguel Ángel Porrúa, 2001.

Brady, James E. "La importancia de las cuevas artificiales para el entendimiento de los espacios sagrados en Mesoamérica”. Espacios mayas: representaciones, usos, creencias. Eds. Alain Breton y otros. México: Universidad Nacional Autónoma de México / Centro Francés de Estudios Mexicanos y Centroamericanos, 2003.

Brady, James E. y Juan Luis Bonor Villarejo. "Las cavernas en la geografia sagrada de los mayas". Perspectivas antropológicas en el mundo maya. Coords. María Josefa Iglesias y Francesc Ligorred Perramon. Madrid: Sociedad Española de Estudios Mayas, 1993.

Broda, Johanna. "Introducción”. Cosmovisión, ritual e identidad de los pueblos indígenas de México. Coords. Johanna Broda y Félix Báez-Jorge. México: Consejo Nacional para la Cultura y las Artes / Fondo de Cultura Económica, 2001. 
Broda, Johanna y Alejandro Robles. "De rocas y aires en la cosmovisión indígena: culto a los cerros y al viento en el municipio de Tepoztlán”. Historia $y$ vida ceremonial en las comunidades mesoamericanas: los ritos agrícolas. Coords. Johanna Broda y Catharine Good Eshelman. México: Consejo Nacional para la Cultura y las Artes / Instituto Nacional de Antropología e Historia / Universidad Nacional Autónoma de México, 2004.

Carrillo González, Juan. "Entre 'idolatrías y extirpaciones'. Ritos mayas en la provincia de Yucatán”. Con el pasado en la mira. Estudios historiográficos. Coord. Paola Peniche Moreno. Mérida: Fondo Institucional de Fomento Regional para el Desarrollo Científico, Tecnológico y de Innovación / Consejo Nacional de Ciencia y Tecnología, 2013.

. "Naguales en las poblaciones mayas coloniales. Más allá del sustrato, la transfiguración y la memoria”. Indiana 35.1 (2018): 39-65.

. "Ritualidad y pensamiento de antigua impronta en los pueblos mayas de la Verapaz, Guatemala, 1550-1813”. Ciencias Sociales y Humanidades 3.2 (2016): 61-70.

. "Tunk'ul: Análisis de un instrumento musical maya en contextos rituales durante la Colonia”. Flower World, Music Archaeology of the Americas / Mundo Florido, Arqueomusicología de las Américas 1 (2012): 127-136.

Cruz Cortés, Noemí. Las señoras de la luna. México: Universidad Nacional Autónoma de México, 2005.

De la Garza, Mercedes. Sueño y alucinación en el mundo náhuatl y maya. México: Universidad Nacional Autónoma de México, 1990.

Espinosa Pineda, Gabriel. "La fauna de Ehécatl”. Animales y plantas en la cosmovisión mesoamericana. Coord. Yolotl González Torres. México: Consejo Nacional para la Cultura y las Artes / Instituto Nacional de Antropología e Historia / Plaza y Valdés, 2001.

Espinosa, María Alejandra y Gabriela Armentano. "Siliceous Raw Material Sources at La Sierrita de Ticul, Yucatan, Mexico: A First Approach of Lithic Procurement During Late Pleistocene and Early Holocene in the Maya Lowlands". The Exploitation of Raw Materials in Prehistory: Sourcing, Processing and Distribution. Eds. Telmo Pereira y otros. New Castle: Cambridge Scholars Publishing, 2017.

Flores Torres, Jorge. Los mayas y el control cultural. Etnotecnología, mayaeconomía y pensamiento político de los pueblos centro-orientales de Yucatán. México: Universidad Autónoma de Chapingo / Universidad Autónoma de Yucatán, 1997.

Florescano, Enrique. Memoria mexicana. México: Fondo de Cultura Económica, 2004.

García Quintanilla,Alejandra. “El dilema de ah kimsah k'ax, 'el que mata al monte': significados del monte entre los mayas milperos deYucatán”. Mesoamérica 39 (2000): 255-285.

González Licón, Ernesto. Los mayas de la gruta de Loltún, Yucatán, a través de sus materiales arqueológicos. México: Instituto Nacional de Antropología e 
Historia, 1986.

Guzmán Urióstegui, Jesús. “El fogón y la milpa. El espacio entre los mayas de Xohuayán, Yucatán”. Dimensión Antropológica 39 (2007): 101-119.

Hofling, Charles Andrew y Félix Fernando Tesucún. Tojt’an Maya’ Itzaj. Diccionario maya itzaj-castellano. Guatemala: Cholsamaj, 2000.

Le Plongeon, Alice Dixon. Aquí y allá en Yucatán. México: Consejo Nacional para la Cultura y las Artes, 2001.

Limón Olvera, Silvia. Las cuevas y el mito de origen: los casos inca y mexica. México: Consejo Nacional para la Cultura y las Artes, 1990.

López Austin, Alfredo. "Mitos e íconos de la ruptura del Eje Cósmico: un glifo toponímico de las piedras de Tízoc y del Ex-Arzobispado”. Anales del Instituto de Investigaciones Estéticas 89 (2006): 93-134.

. "La magia y la adivinación en la tradición mesoamericana”. Arqueología Mexicana 69 (2004): 20-29.

López Austin, Alfredo y Leonardo López Luján. “El sacrificio humano entre los mexicas”. Arqueología Mexicana 103 (2010): 24-33.

Mercer, Henry C. The Hill-Caves of Yucatan: A Search for Evidence of Man's Antiquity in the Caverns of Central America. Norman:The University of Oklahoma Press, 1975.

Paxton, Merideth. The Cosmos of the Yucatec Maya. Cycles and Steps from the Madrid Codex. Albuquerque: University of New Mexico Press, 2001.

Pedroza, Lisseth. "Cenotes y cuevas inundadas de la península de Yucatán. De los primeros pobladores a la Guerra de Castas". Arqueología Mexicana 105 (2010): 48-52.

Peniche Moreno, Paola. Ámbitos del parentesco: la sociedad maya en tiempos de la Colonia. México: Centro de Investigaciones y Estudios Superiores en Antropología Social / Miguel Ángel Porrúa, 2007.

Restrepo, Luis Fernando. "Estudios subalternos y tiempo insurgente: memorias maya-tzeltal de la rebelión de 1712 en Chiapas". Revista Iberoamericana 201 (2002): 1091-1109.

Rojas, Carmen. "Prácticas mortuorias en los cenotes". Revista de Arqueología Americana 26 (2008): 197-222.

Rojas Rabiela, Teresa y otros. Cultura hidráulica y simbolismo mesoamericano del agua en el México prehispánico. México: Instituto Mexicano de Tecnología del Agua / Centro de Investigaciones y Estudios Superiores en Antropología Social, 2009.

Romero Sandoval, Roberto. Ed. Cuevas y cenotes mayas. Una mirada multidisciplinaria. México: Universidad Nacional Autónoma de México / Centro de Estudios Mayas, 2016.

Sáenz de Santa María, Carmelo. "Una visión etnorreligiosa de la Guatemala de 1704, según fray Antonio Márgil de Jesús”. Revista de Indias 41 (1981): 445-497.

Schele, Linda y Mary Ellen Miller. The Blood of Kings: Dynasty and Ritual in Maya 
Art. Nueva York: George Braziller, 1986.

Scholes, France V. y Eleanor B. Adams. Eds. Don Diego de Quijada, alcalde mayor de Yucatán, 1561-1565. Tomo 1. México:Antigua Librería Robredo de José Porrúa e Hijos, 1938.

Smith, A. Ledyard. Archaeological Reconnaissance in Central Guatemala. Washington: Carnegie Institution of Washington, 1955.

Thomas, Christian. Dir. Las cuevas de Yucatán. La región de Valladolid. Montreuil: Ediciones Xibalbá, 2011. 